\title{
Significant Domains of Life Satisfaction That Affect Suicidal Behavior in Adolescents
}

\author{
Ji Soo Kim ${ }^{1}$, Seo-Hyun Choi ${ }^{1}$, Sang-Eun Lee ${ }^{2,3}$, Chai Won Lee ${ }^{2,3}$, Won-Hyoung Kim ${ }^{1}$, \\ Jae Nam Bae', Jeong Seop Lee', Seri Maeng ${ }^{1}$, Jisung Son ${ }^{1}$, and Hyeyoung Kim ${ }^{1,4}$ \\ ${ }^{1}$ Department of Psychiatry, Inha University Hospital, Incheon, Korea \\ ${ }^{2}$ Incheon Jung-gu Community Mental Health Center, Incheon, Korea \\ ${ }^{3}$ Department of Nursing, Inha University College of Medicine, Incheon, Korea \\ ${ }^{4}$ Department of Psychiatry, Seoul National University College of Medicine, Seoul, Korea
}

\begin{abstract}
Objectives: Adolescent suicide is a serious national issue in Korea. Recently, life satisfaction has been recognized as a major factor related to this issue. The main purpose of this study was to identify the domains of life satisfaction that affect suicidal behavior in adolescence. Methods: Data were collected from eight middle schools in Incheon, Korea. A total of 1297 students answered questions regarding their demographic characteristics, happiness, self-related life satisfaction domains (appearance, leisure time, physical health, and mental health), depressive symptoms, and suicidal behavior.

Results: In the Spearman correlation analysis, female sex, perceived socioeconomic status (SES), happiness, and all four self-related satisfaction scores showed significant correlations with depression and suicidality. Multivariate regression analysis suggested that suicidality was significantly affected by perceived SES, satisfaction with appearance, mental health satisfaction, and depression. Finally, depression was identified as a partial mediator of the association between mental health satisfaction and suicidality, and a complete mediator of the association between female sex and suicidality.

Conclusion: Perceived SES, satisfaction with appearance, and mental health satisfaction significantly affected students' suicidality, with or without the effect of depression. Health authorities, educators, and family members must be aware of this to identify adolescents at suicide risk earlier.
\end{abstract}

Key Words: Suicide; Satisfaction; Physical appearance; Mental health; Depression; Adolescent.

Received: February 9, 2021 / Revision: March 9, 2021 / Accepted: March 23, 2021

Address for correspondence: Hyeyoung Kim, Department of Psychiatry, Inha University Hospital, 27 Inhang-ro, Jung-gu, Incheon 22332, Korea

Tel: +82-32-890-2582, Fax: +82-32-890-3536, E-mail: kimhy.md@gmail.com

\section{INTRODUCTION}

Suicide awareness is a critical social issue in Korea. Korea's suicide rate was the fourth highest worldwide and the highest among the members of the Organization for Economic Cooperation and Development (OECD) in 2019 [1,2]. Although the suicide rate in Korea steadily declined from 31.0 to 24.3 per 100000 people from 2009 to 2017, this rate rose again by 2.3 per 100000 people in 2018 and by 0.3 per 100000 people in 2019. According to age-specific trends during this period, this increase was the highest among individuals in their teens and twenties. In teenagers, the suicide rate has not fallen significantly over the past decade [3]. This may indicate that interventions to prevent adolescent suicides have not been well established.

This is an Open Access article distributed under the terms of the Creative Commons Attribution Non-Commercial License (https://creativecommons.org/licenses/by-nc/4.0) which permits unrestricted non-commercial use, distribution, and reproduction in any medium, provided the original work is properly cited.
Given that adolescents are intrinsically immature and vulnerable to external stimuli, the psychological structures that lead to adolescent suicidality must be viewed differently from those of adults. Previous studies on adolescent suicides have included several suicidal risk factors. These include internal factors (e.g., depression, hopelessness, stress, self-esteem, and attitudes toward suicide) [4-6], interpersonal factors (e.g., school and family life) [7], and psychiatric factors (e.g., mood disorders and substance abuse) $[8,9]$.

Research regarding life satisfaction has been ongoing since the late 20th century. More recently, research into the life satisfaction of adolescents has been considered important. Life satisfaction is a cognitive and subjective judgment of life, where both global satisfaction and domain life satisfaction must be considered [10]. Global life satisfaction refers to a comprehensive judgment of one's life. On the other hand, domain satisfaction refers to satisfaction with specific areas of one's life. These may vary but are commonly divided into income, work, 
relationships, and self $[11,12]$. There has been a continuous effort to link global satisfaction and domain satisfaction with suicidal behavior. A significant association was reported between global life satisfaction, poor mental and physical health, and suicidal behavior [13]. In a Japanese study, life satisfaction was divided into home life, work, income, leisure, relationships, and residence to study the connection between the domain satisfaction of residence and adult suicide deaths [14]. A crosssectional adolescent study in China included satisfaction with oneself, which was not significantly associated with suicidal ideation [15]. Another study conducted in Korea revealed that self-satisfaction significantly affected suicidal ideation among middle school students [6].

The primary goal of our study was to identify domain satisfaction specific to the "self" that significantly affected suicidal behavior. Additionally, we examined the mediation effect of depression on the association between these factors and suicidality. To our knowledge, this is the first adolescent study to investigate the significant domains of life satisfaction, especially those focused on the "self," that affect suicidal ideation, plan, or attempts.

\section{METHODS}

\section{Participants}

This study was a secondary analysis of an adolescent suicide survey that examined the mental health of adolescents, which included depression, life satisfaction, and suicidality, and their attitudes toward suicidal behavior. The original study sample included 1385 eighth-grade students from eight middle schools located in Jung-gu, Incheon [16]. Excluding 88 respondents, 1297 valid respondents were included in the analysis.

\section{Procedure}

The survey was conducted in September 2018. Homeroom teachers explained the details of the study to the students, who then completed a questionnaire distributed to them.

\section{Measurement}

We used a questionnaire that included questions related to demographic characteristics, happiness, life satisfaction, symptoms of depression, and suicidal behavior. Demographic characteristics included sex, number of family members, religious affiliation, perceived socioeconomic status (SES), and exercise.

\section{Happiness and life satisfaction}

Happiness was rated on a four-point Likert scale, from 1 (very happy) to 4 (not at all happy), in response to "How happy/unhappy do you think you are now?." Life satisfaction included four self-related domains (appearance, leisure time, physical health, and mental health): "How satisfied/or dissatisfied you are with your appearance?"; "Do you think you have/ do not have enough leisure time?"; "How good/bad is your physical health?"; and "How good/bad is your mental health?." Appearance satisfaction and leisure time satisfaction were rated on a four-point Likert scale, from 1 (very satisfied) to 4 (not at all satisfied). Physical and mental health satisfaction were rated on a five-point Likert scale ranging from 1 (very good) to 5 (not at all good).

\section{Center for Epidemiologic Studies Depression Scale-Revised (CESD-R)}

The Center for Epidemiologic Studies Depression Scale (CESD), first developed by Radloff [17] and revised by Eaton et al. [18], was used to assess the severity of depression. Lee et al. [19] translated and standardized this scale into a Korean version. According to the optimal cut-off value suggested in the study, we classified those who scored less than 13 points as low risk and those who scored more than 13 points as high risk, while using depression as a binary variable [19].

\section{Suicidal behavior}

Questions related to suicidal behavior or suicidality were selected from the Korean version of the Composite International Diagnostic Interview (K-CIDI). CIDI, an international diagnostic tool for mental disorders, was standardized to a Korean version by Cho et al. [20]. Suicidality was defined as responding "yes" to the questions: "Have you ever seriously thought about committing suicide?"; "Have you ever made a plan to commit suicide?"; and "Have you ever attempted suicide?."

\section{Statistical analysis}

"Non-response/no idea" was converted to N/A and was automatically excluded from the analysis. Histogram and Shapiro-Wilk normality tests confirmed that the data did not have a normal distribution. All analyses were conducted using R Studio version 1.3.1073 (Delaware Public Benefit Corporation, Boston, MA, USA).

We used the Spearman correlation analysis to explore how and in what direction depression and suicidality are correlated with other characteristics of adolescents. Multivariate logistic regression analyses were conducted to determine the independent association of each variable with suicidal ideation, suicidal plans, and suicide attempts. The fit of the model was confirmed using the Chi-square test and maximum likelihood test. Since all variance inflation factor (VIF) values were below 2.5 , multicollinearity among variables was ruled out. According to Belsley et al. [21], a VIF above 10 suggests multicollinearity. Additionally, using the Baron and Kenny method [22], we 
examined the mediation effect of depression on the associations found in the multivariate analyses. The Sobel test verified the significance of the mediation effect.

\section{Ethical statement}

The Institutional Review Board of Inha University Hospital (registration number: 2018-06-032) approved the study protocol and waiving of informed consent.

\section{RESULTS}

\section{Characteristics of the study population}

As presented in Table 1, 653 of the respondents (50.3\%) were male and 598 (46.1\%) were female. More than half (52.8\%) the respondents lived with four family members including themselves, more than half (58\%) had no religious affiliation, and most of them (78.3\%) exercised regularly or irregularly. In the perceived SES domain, "middle" or "upper-middle" accounted for the largest percentage (65.3\%) of respondents.

Among the respondents, 189 (14.6\%) responded that they were unhappy, and 351 (26.9\%) and 388 (29.9\%) were not satisfied with their appearance or leisure time, respectively. In terms of physical and mental health satisfaction, 127 (9.8\%) and $119(9.2 \%)$ said that they were not satisfied. The mean score of Korean version of CESD-R (K-CESD-R), including all students, was 9.61 [standard deviation (SD) 14.11], and 337 (26\%) were at high risk for depression, with a mean score of 28.63 (SD 12.63). Regarding suicidality, 353 (27.2\%), 122 (9.4\%), and 97 (7.5\%) had suicidal ideation, suicidal plans, and suicidal attempts, respectively.

\section{Correlation between the variables, depression, and suicidality}

Regarding all the characteristics included in Table 1, a Spearman correlation analysis was performed to determine how the various factors correlated with depression and suicidality (Table 2). Female sex, less exercise, lower perceived SES, unhappiness, or lower satisfaction with oneself tended to expose adolescents to depression and suicidality. Depression and suicidality also had positive correlations with each other. The correlation between exercise and suicidality did not exist for suicidal plans or attempts. The number of family members or religious affiliations showed no significant correlation with suicidality.

In particular, the correlation between suicidal ideation and happiness, mental health satisfaction, and depression approached a moderate level. For suicidal plans or attempts, the strength of the correlation was found to be weaker than that of suicidal ideation.

\section{Independent effect of variables on suicidality}

Multivariate logistic regression analyses helped identify the significant factors that have a consistent effect on suicidal ideation, suicidal plans, and suicidal attempts (Table 3). Before the multivariate adjustment, most variables were significant, except for the number of family members and religious affiliation, which showed no correlation with suicidality.

However, after the multivariate adjustment, satisfaction with appearance, mental health satisfaction, and depression were independently significant for suicidal ideation and demonstrated similar results for suicidal plans or attempts. That is, low satisfaction with appearance [suicidal ideation: odds ratio $(\mathrm{OR})=1.54, \mathrm{p}<0.001$; suicidal attempts: $\mathrm{OR}=1.46, \mathrm{p}=0.047]$, low mental health satisfaction (suicidal ideation: $\mathrm{OR}=1.69$, $\mathrm{p}<0.001$; suicidal plans: $\mathrm{OR}=1.91, \mathrm{p}<0.001$; suicidal attempts: $\mathrm{OR}=1.59, \mathrm{p}=0.005$ ), or a high risk of depression (suicidal ideation: $\mathrm{OR}=2.79, \mathrm{p}<0.001$; suicidal plans: $\mathrm{OR}=2.80, \mathrm{p}<0.001$; suicidal attempts: $O R=4.00 \mathrm{p}<0.001)$ increased the risk of suicidality. Perceived SES was significant only for suicidal plans. Many of the factors that were significant before adjustment were no longer significant. Sex did not affect suicidality, and neither did happiness, satisfaction with leisure time, or physical health.

\section{Mediation analyses}

Each step of the mediation analyses for depression between the variables and suicidality is shown in Supplementary Table 1 (in the online-only Data Supplement). This implies that the mediation effect of depression existed only between sex or mental health satisfaction and suicidality (except between sex and suicidal plans). This was confirmed by the Sobel test (Supplementary Table 2 in the online-only Data Supplement).

Fig. 1 shows a summary of the mediation effect of depression on suicidality, as discussed above. The only factors mediated by depression were sex and mental health satisfaction. Sex was significant for depression $\left(\beta_{\mathrm{Aa}}=0.721, \mathrm{p}<0.001\right)$, indicating that females were more likely to be depressed. Its effect on suicidal ideation $\left(\beta_{\mathrm{Ac}}=0.427, \mathrm{p}<0.05\right)$ and suicide attempts $\left(\beta_{\mathrm{Bc}}=\right.$ $0.577, \mathrm{p}<0.05$ ) disappeared when depression was introduced into the model (suicidal ideation: $\beta_{A c}=0.319, p=0.065$; suicidal attempts: $\beta_{\mathrm{BC}}=0.398, \mathrm{p}=0.163$ ). Therefore, depression was a complete mediator of the effect of females on suicidal ideation or attempts. Mental health satisfaction was also a significant factor for depression $\left(\beta_{\mathrm{Ca}}=0.741, \mathrm{p}<0.001\right)$. Its effect on suicidal ideation $\left(\beta_{\mathrm{Cc}}=0.639, \mathrm{p}<0.001\right)$, suicidal plans $\left(\beta_{\mathrm{Dc}}=0.762, \mathrm{p}<\right.$ $0.001)$, and suicidal attempts $\left(\beta_{\mathrm{Ec}}=0.607, \mathrm{p}<0.001\right)$ decreased when depression was introduced into the model (suicidal ideation: $\beta_{C c^{\prime}}=0.522, \mathrm{p}<0.001$; suicidal plans: $\beta_{D^{c}}=0.649, \mathrm{p}<0.001$; suicide attempts: $\left.\beta_{\mathrm{EC}}=0.463, \mathrm{p}<0.001\right)$. Accordingly, depression was a partial mediator of the effect of mental health satisfac- 
Table 1. Characteristics of study population

\begin{tabular}{|c|c|}
\hline Characteristics & Values \\
\hline \multicolumn{2}{|l|}{ Sex } \\
\hline Male & $653(50.3)$ \\
\hline Female & $598(46.1)$ \\
\hline \multicolumn{2}{|l|}{ Number of family members } \\
\hline$\leq 3$ & $231(17.8)$ \\
\hline 4 & $685(52.8)$ \\
\hline$\geq 5$ & $378(29.1)$ \\
\hline \multicolumn{2}{|l|}{ Religious affiliation } \\
\hline No & $752(58.0)$ \\
\hline Yes & $535(41.3)$ \\
\hline \multicolumn{2}{|l|}{ Exercise } \\
\hline Regular & $367(28.3)$ \\
\hline Irregular & $649(50.0)$ \\
\hline Never & $280(21.6)$ \\
\hline \multicolumn{2}{|c|}{ Perceived socioeconomic status } \\
\hline Upper & $143(11)$ \\
\hline Upper-middle & $351(27.1)$ \\
\hline Middle & $496(38.2)$ \\
\hline Lower-middle & $120(9.3)$ \\
\hline Lower & $31(2.4)$ \\
\hline \multicolumn{2}{|l|}{ Happiness } \\
\hline Very happy & $427(32.9)$ \\
\hline Somewhat happy & $637(49.1)$ \\
\hline Not very happy & $161(12.4)$ \\
\hline Not at all happy & $28(2.2)$ \\
\hline \multicolumn{2}{|l|}{ Appearance satisfaction } \\
\hline Very satisfied & $214(16.5)$ \\
\hline Somewhat satisfied & $643(49.6)$ \\
\hline Not very satisfied & $282(21.7)$ \\
\hline Not at all satisfied & $69(5.2)$ \\
\hline \multicolumn{2}{|l|}{ Leisure time satisfaction } \\
\hline Very satisfied & $314(24.2)$ \\
\hline Somewhat satisfied & $560(43.2)$ \\
\hline Not very satisfied & $314(24.2)$ \\
\hline Not at all satisfied & $74(5.7)$ \\
\hline \multicolumn{2}{|l|}{ Physical health satisfaction } \\
\hline Very good & $310(23.9)$ \\
\hline Somewhat good & $492(37.9)$ \\
\hline Neutral & $368(28.4)$ \\
\hline Not very good & $113(8.7)$ \\
\hline Not at all good & $14(1.1)$ \\
\hline \multicolumn{2}{|l|}{ Mental health satisfaction } \\
\hline Very good & $450(34.7)$ \\
\hline Somewhat good & $437(33.7)$ \\
\hline Neutral & $290(22.4)$ \\
\hline Not very good & $92(7.1)$ \\
\hline Not at all good & $27(2.1)$ \\
\hline
\end{tabular}

Table 1. Characteristics of study population (continued)

\begin{tabular}{lc}
\hline \multicolumn{1}{c}{ Characteristics } & Values \\
\hline Depression (K-CESD-R) & $960(74)$ \\
Low risk (total score <13) & $2.93(3.45)$ \\
Mean (SD) & $337(26)$ \\
High risk (total score $\geq 13)$ & $28.63(12.63)$ \\
$\quad$ Mean (SD) & $9.61(14.11)$ \\
Total mean (SD) & \\
History of suicidal ideation & $912(70.3)$ \\
No & $353(27.2)$ \\
Yes & $1133(87.4)$ \\
History of suicidal plan & $122(9.4)$ \\
No & $1148(88.5)$ \\
Yes & $97(7.5)$ \\
History of suicidal attempt & \\
No & \\
Yes & \\
\hline Values are presented as $n$ (\%) unless otherwise indicated. Stu- \\
dents with "non-response/no idea" were not counted. K- \\
CESD-R: Korean version of Center for Epidemiologic Studies \\
Depression Scale-Revised (CESD-R), SD: standard deviation
\end{tabular}

Table 2. Spearman correlation analysis between variables and depression and suicidality

\begin{tabular}{lcccc}
\hline & DEP & SI & SP & SA \\
\hline Sex & $0.208^{\ddagger}$ & $0.166^{\ddagger}$ & $0.097^{\ddagger}$ & $0.101^{\ddagger}$ \\
FAM & -0.057 & -0.061 & 0.003 & -0.001 \\
RELI & $-0.070^{\ddagger}$ & -0.013 & -0.051 & -0.032 \\
EXE & $0.125^{\ddagger}$ & $0.098^{\ddagger}$ & 0.029 & 0.035 \\
SES & $0.215^{\ddagger}$ & $0.169^{\ddagger}$ & $0.154^{\ddagger}$ & $0.098^{\ddagger}$ \\
HAP & $0.393^{\ddagger}$ & $0.313^{\ddagger}$ & $0.215^{\ddagger}$ & $0.181^{\ddagger}$ \\
AS & $0.281^{\ddagger}$ & $0.287^{\ddagger}$ & $0.156^{\ddagger}$ & $0.164^{\ddagger}$ \\
LTS & $0.225^{\ddagger}$ & $0.195^{\ddagger}$ & $0.093^{*}$ & $0.044^{*}$ \\
PHS & $0.273^{\ddagger}$ & $0.216^{\ddagger}$ & $0.136^{\ddagger}$ & $0.135^{\ddagger}$ \\
MHS & $0.443^{\ddagger}$ & $0.382^{\ddagger}$ & $0.275^{\ddagger}$ & $0.223^{\ddagger}$ \\
DEP & 1.000 & $0.383^{\ddagger}$ & $0.291^{\ddagger}$ & $0.286^{\ddagger}$ \\
\hline
\end{tabular}

${ }^{*} p<0.05,{ }^{\dagger} p<0.01,{ }^{\ddagger} p<0.001$. AS: appearance satisfaction, DEP: depression, EXE: exercise, FAM: number of family members, HAP: happiness, LTS: leisure time satisfaction, MHS: mental health satisfaction, PHS: physical health satisfaction, RELI: religious affiliation, SA: suicidal attempt, SES: perceived socioeconomic status, SI: suicidal ideation, SP: suicidal plan

tion on suicidality.

\section{DISCUSSION}

According to this study, in addition to depression, various factors that constitute quality of life, such as happiness, perceived SES, and life satisfaction in the domains of appearance, leisure time, and physical and mental health, were significantly correlated with suicidal behavior. It is also worth noting that these are subjective indicators. Among these, perceived SES, 
satisfaction with appearance, mental health satisfaction, and depression independently revealed significant effects on suicidal behavior in the multivariate regression analysis. In other words, a negatively perceived SES or a lower domain satisfaction serve as important risk factors for suicidality separately, even after considering the effect of depression, which is a well-

Table 3. Multivariate logistic regression assessing the effects of variables on suicidal ideation, suicidal plan, and suicidal attempt

\begin{tabular}{|c|c|c|c|c|c|c|}
\hline & \multicolumn{2}{|c|}{ Suicidal ideation } & \multicolumn{2}{|c|}{ Suicidal plan } & \multicolumn{2}{|c|}{ Suicidal attempt } \\
\hline & Crude & Adjusted & Crude & Adjusted & Crude & Adjusted \\
\hline Sex & $2.15^{\ddagger}(1.61,2.88)$ & $1.38(0.98,1.93)$ & $1.92^{\dagger}(1.22,3.01)$ & $1.26(0.76,2.09)$ & $2.20^{\dagger}(1.33,3.63)$ & $1.49(0.85,2.61)$ \\
\hline FAM & $0.88(0.76,1.02)$ & $0.93(0.79,1.09)$ & $1.01(0.81,1.26)$ & $1.10(0.88,1.38)$ & $1.02(0.80,1.29)$ & $1.13(0.89,1.43)$ \\
\hline RELI & $0.97(0.73,1.30)$ & $1.12(0.80,1.55)$ & $0.73(0.47,1.13)$ & $0.74(0.46,1.19)$ & $0.79(0.49,1.27)$ & $0.87(0.52,1.46)$ \\
\hline EXE & $1.38^{\ddagger}(1.12,1.69)$ & $0.94(0.73,1.21)$ & $1.14(0.84,1.56)$ & $0.81(0.56,1.17)$ & $1.20(0.85,1.69)$ & $0.80(0.54,1.19)$ \\
\hline SES & $1.56^{\ddagger}(1.33,1.84)$ & $1.05(0.87,1.28)$ & $1.89 \ddagger(1.48,2.41)$ & $1.40 *(1.07,1.84)$ & $1.62^{\ddagger}(1.25,2.11)$ & $1.11(0.83,1.49)$ \\
\hline HAP & $2.91^{\ddagger}(2.33,3.64)$ & $1.15(0.86,1.55)$ & $2.64^{\ddagger}(1.98,3.54)$ & $1.11(0.73,1.67)$ & $2.54^{\ddagger}(1.85,3.47)$ & $1.08(0.69,1.68)$ \\
\hline AS & $2.53^{\ddagger}(2.06,3.12)$ & $1.54^{\ddagger}(1.20,1.98)$ & $1.96^{\ddagger}(1.48,2.61)$ & $1.15(0.81,1.62)$ & $2.30^{\ddagger}(1.69,3.14)$ & $1.46 *(1.00,2.12)$ \\
\hline LTS & $1.67^{\ddagger}(1.41,1.99)$ & $1.12(0.91,1.39)$ & $1.36 *(1.05,1.75)$ & $0.83(0.60,1.14)$ & $1.24(0.93,1.64)$ & $0.71(0.50,1.01)$ \\
\hline PHS & $1.73^{\ddagger}(1.48,2.02)$ & $0.98(0.80,1.22)$ & $1.54^{\ddagger}(1.23,1.93)$ & $0.85(0.62,1.15)$ & $1.70^{\ddagger}(1.33,2.17)$ & $1.01(0.73,1.39)$ \\
\hline MHS & $2.55^{\ddagger}(2.17,3.01)$ & $1.69^{\ddagger}(1.36,2.09)$ & $2.43^{\ddagger}(1.97,3.00)$ & $1.91^{\ddagger}(1.41,2.59)$ & $2.31^{\ddagger}(1.84,2.90)$ & $1.59^{\dagger}(1.15,2.20)$ \\
\hline DEP & $6.27^{\ddagger}(4.55,8.63)$ & $2.79^{\ddagger}(1.90,4.08)$ & $6.12^{\ddagger}(3.87,9.68)$ & $2.80^{\ddagger}(1.60,4.93)$ & $7.59 \ddagger(4.54,12.69)$ & $4.00^{\ddagger}(2.16,7.40)$ \\
\hline DF & \multicolumn{2}{|c|}{959} & \multicolumn{2}{|c|}{948} & \multicolumn{2}{|c|}{943} \\
\hline AIC & \multicolumn{2}{|c|}{937.49} & \multicolumn{2}{|c|}{513.15} & \multicolumn{2}{|c|}{448.64} \\
\hline
\end{tabular}

Values are presented as odds ratio (95\% confidence interval) unless otherwise indicated. ${ }^{*} p<0.05,{ }^{\dagger} p<0.01,{ }^{\ddagger} p<0.001$. AlC: Akaike information criterion, AS: appearance satisfaction, DEP: depression, DF: degree of freedom, EXE: exercise, FAM: number of family members, HAP: happiness, LTS: leisure time satisfaction, MHS: mental health satisfaction, PHS: physical health satisfaction, RELI: religious affiliation, SES: perceived socioeconomic status
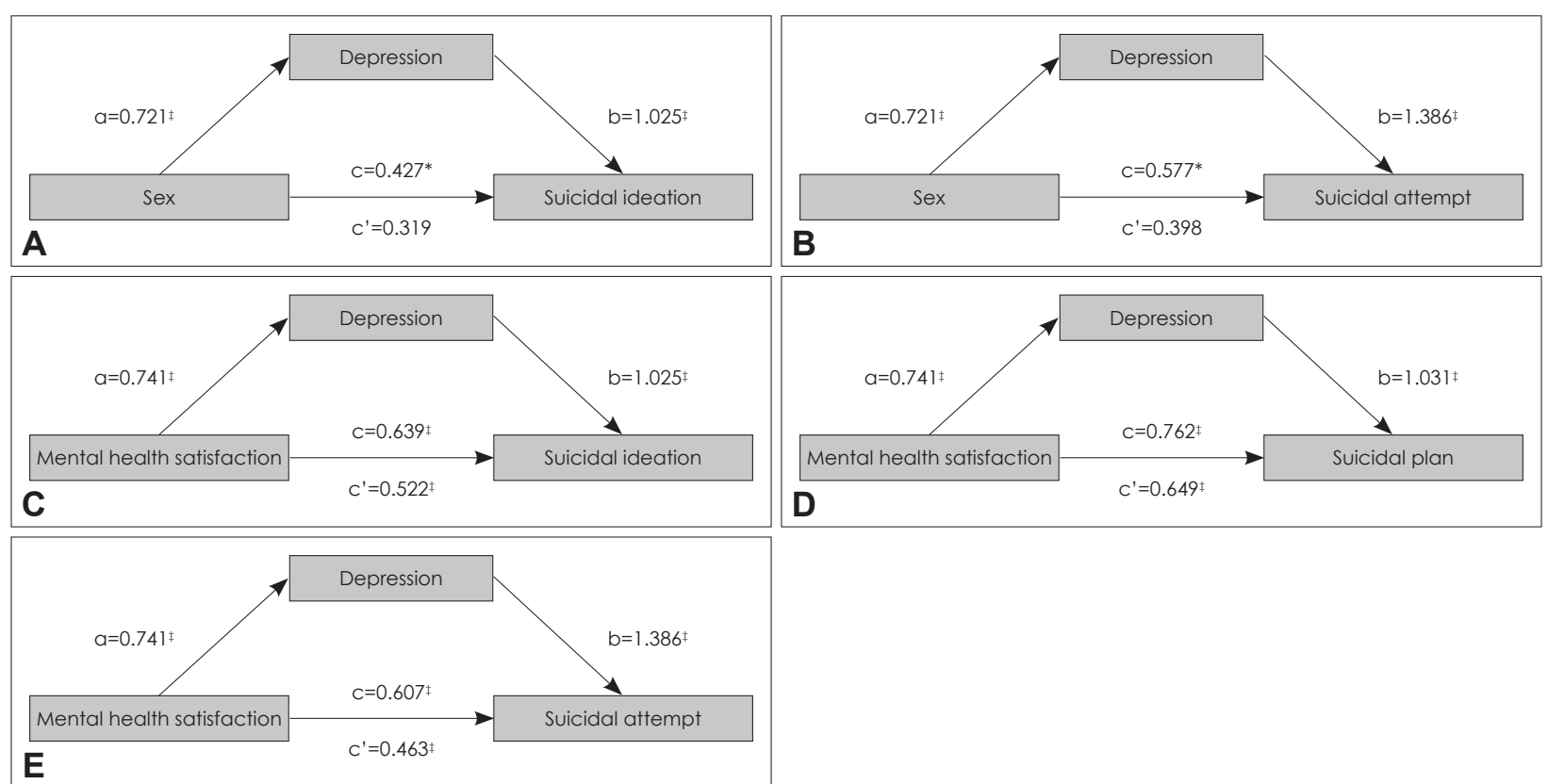

Fig. 1. Mediation model of independent variables, depression, and suicidal behavior. (A-E) Shows the significant results of mediation analysis of depression toward suicidal ideation, suicidal plan, and suicidal attempt. A: Depression mediates between sex and suicidal ideation. B: Depression mediates between sex and suicidal attempt. C: Depression mediates between mental health satisfaction and suicidal ideation. D: Depression mediates between mental health satisfaction and suicidal plan. E: Depression mediates between mental health satisfaction and suicidal attempt. Logistic regression coefficients are as follows: a=for the association of independent variable [which is shown significant both in step 1 and step 2 from Supplementary Table 1 (in the online-only Data Supplement)] with depression, $b=$ for the association of depression with suicidality [from step 3 in Supplementary Table 1 (in the online-only Data Supplement)], c=for total effect [association of independent variable with suicidality, from step 2 in Supplementary Table 1 (in the online-only Data Supplement)], c'=for direct effect [association of independent variable with suicidality from step 3 in Supplementary Table 1 (in the online-only Data Supplement)]. Depression had no mediation effect between other independent variables and suicidality. ${ }^{*} p<0.05,{ }^{\ddagger} p<0.001$. 
known critical risk factor for suicide $[4,5,23,24]$. On the other hand, there was a small difference in the regression results for suicidal plans. In adolescence, suicidal ideation or an attempt may not necessarily be accompanied by a suicidal plan because of their immature and impulsive nature.

In previous research, global life satisfaction scales, such as the Multidimensional Students' Life Satisfaction Scale [25] or the Satisfaction with Life Scale [10], were often used, rather than studying the effect of individual domain satisfaction. In contrast, this study investigated the effect of self-related domain satisfaction on suicidal behavior and the effect of depression as a mediator to help further clarify the internal and psychological structure of adolescents.

In terms of quality of life, a subjective assessment is more important than just objective figures related to economic conditions [26]. It is not uncommon for adults to attempt suicide out of pessimism regarding their SES. In this study, a negatively perceived SES also significantly affected adolescents' suicidal plans, which was not mediated by depression. This may be because they are under the emotional and cognitive influences of their parents.

A positive feeling regarding one's physical features or appearance establishes self-confidence and self-esteem in adolescence and enables a healthy mindset in adulthood. However, today's generation of adolescents is more likely to have a distorted perception of their appearance as they are exposed to media outlets that incite lookism. This experience makes them consciously and unconsciously evaluate their physical appearance against an unrealistic standard, which negatively affects their mental health. Dissatisfaction with one's appearance in adolescence can lead not only to depression, but also to suicidal ideation $[23,27]$. We confirmed that dissatisfaction with appearance contributed to suicidal ideation and suicide attempts, and this association was not mediated by depression.

Mental health satisfaction was the second most important factor affecting suicidal behavior. This effect was mediated by depression; however, it was also present without depression. The perception of mental health has previously been reported as a significant variable for suicidal ideation throughout adolescence. However, no analysis of suicidal plans or attempts has been made [5]. In comparison, physical health satisfaction was not a significant factor. In studies that did not distinguish between physical and mental health, results concerning the subjective assessment of overall health were inconsistent. Some studies have shown a significant effect on suicidal ideation or plans, but not on suicidal attempts [28], while others showed a significant effect on all suicidal behaviors [24].

Happiness has often been mentioned in relation to life satisfaction and mental health. It also showed a significant correlation with suicidal behavior in this study. Nevertheless, no significant impact was found on multivariate regression, and no mediating effects of depression were identified. This could mean that adolescents perceive happiness differently from mental health or that happiness interacts with various factors, including variables not investigated in this study. The ambiguity of happiness and the lack of standardized scales should also be considered.

Sex showed no significant results in the multivariate regression, unlike previous studies that reported female sex as a risk factor for suicidal behavior $[6,15,23,24]$. This was because depression completely mediated the association between sex and suicidal behavior. This means that female sex contributed to suicidal ideation and suicidal attempts only indirectly through depression.

The study limitations should be noted. First, we did not use a validated life satisfaction scale. Further studies using a validated multidimensional measure, such as the Youth Happiness Index [29], which includes several self-related domains, are needed. Second, only the eighth graders of a particular region participated, which limits generalization. Nevertheless, our results were in line with those of previous studies, which showed that life satisfaction was a significant factor for suicidality $[5,6,13,15]$. Third, since the psychiatric histories of the participants were not known, it was difficult to determine whether mental illnesses other than depression affected the study results. Fourth, the results did not reflect the type of school or subregional differences, possibly underestimating the effect of confounding factors. Fifth, the ambiguity of happiness is another limitation. Happiness is often described as subjective well-being. According to the OECD, subjective well-being is a good mental state, including all the various evaluations that people make of their lives and the affective reactions to their experiences [30]. However, it is highly likely that eighth graders rated happiness only as their temporary emotion in response to the question "How happy do you think you are now?." The insignificant result of happiness in the multivariate regression analysis may also support this finding. In future studies, participants should be presented with specific definitions of happiness. Finally, the evaluation of suicidal behavior was oversimplified by including lifetime suicidal behaviors and not excluding non-suicidal self-harm behaviors. Therefore, the association of the variables with suicidality may have been overestimated. Given that previous suicide-related behaviors themselves are important risk factors for suicide [9], our results have significant implications for predicting and preventing suicide risk.

\section{CONCLUSION}

This study proposes that life satisfaction or the subjective 
assessment of the quality of life, significantly affects suicidal ideation, planning, and attempts. Among them, self-satisfaction with appearance and mental health has a critical impact on adolescent suicidality. Additionally, depression not only partially mediates the association between mental health satisfaction and suicidality, but also completely mediates the association between female sex and suicidality. Therefore, female adolescents require adequate consideration of their emotional sensitivity and early encouragement to obtain professional help for depression. Above all, the subjective assessments of appearance, mental health, and depression will assist in screening for the risk of suicidal behavior. Health authorities, educators, and family members require instruction on how to appreciate and respect adolescents' interests in their appearance and mental health and improve negative self-perceptions.

\section{Supplementary Materials}

The online-only Data Supplement is available with this article at https://doi.org/10.5765/jkacap.210004.

\section{Acknowledgments}

This research was conducted as part of an adolescent suicide prevention program funded by the Incheon Jung-gu Community Mental Health Center in Korea.

\section{Conflicts of Interest}

The authors have no potential conflicts of interest to disclose.

\section{Author Contributions}

Conceptualization: Ji Soo Kim, Won-Hyoung Kim, Hyeyoung Kim. Data curation: all authors. Investigation: all authors. Project administration: Sang-Eun Lee, Chai Won Lee, Hyeyoung Kim. Supervision: Hyeyoung Kim. Validation: Won-Hyoung Kim, Jae-Nam Bae, Jeong Seop Lee, Hyeyoung Kim. Writing_original draft: Ji Soo Kim. Writing—review \& editing: Hyeyoung Kim.

\section{ORCID iDs}

Ji Soo Kim Seo-Hyun Choi Sang-Eun Lee Chai Won Lee Won-Hyoung Kim Jae Nam Bae Jeong Seop Lee Seri Maeng Jisung Son Hyeyoung Kim https://orcid.org/0000-0002-5795-541X https://orcid.org/0000-0002-2726-5610 https://orcid.org/0000-0003-3459-1446 https://orcid.org/0000-0002-9744-9028 https://orcid.org/0000-0002-6650-3685 https://orcid.org/0000-0002-5024-6231 https://orcid.org/0000-0001-5585-0334 https://orcid.org/0000-0001-6850-5548 https://orcid.org/0000-0002-3218-6829 https://orcid.org/0000-0002-2313-8892

\section{REFERENCES}

1) World Population Review. Suicide rate by country 2021. [cited 2021 Jan 5]. Available from URL: https://worldpopulationreview.com/ country-rankings/suicide-rate-by-country.

2) Organization for Economic Cooperation and Development (OECD). Suicide rates. [cited 2020 Dec 15]. Available from URL: https:// data.oecd.org/healthstat/suicide-rates.htm.
3) Statistics Korea. 2019 Korea cause of death statistics. [cited 2020 Dec 15]. Available from URL: http://kostat.go.kr/portal/korea/ kor_nw/1/6/2/index.board?bmode $=$ read\&bSeq $=\& a S e q=385219 \& p$ ageNo $=1 \&$ row $\mathrm{Num}=10 \&$ navCount $=10 \&$ currPg $=\&$ searchInfo $=\& \mathrm{~s}$ Target $=$ title \&sTxt $=$.

4) Reifman A, Windle M. Adolescent suicidal behaviors as a function of depression, hopelessness, alcohol use, and social support: a longitudinal investigation. Am J Community Psychol 1995;23: 329-354.

5) Kim WK. The effects of psychological factors in suicidal ideation among Korean youth. Studies on Korean Youth 2014;25:199-231.

6) Song MJ. The influence on suicide thought of attitude to death and satisfaction about life of middle school students II: including difference analysis between 2016 and 2011. The Korean Journal of Applied Developmental Psychology 2016;5:95-108.

7) Gould MS, Fisher P, Parides M, Flory M, Shaffer D. Psychosocial risk factors of child and adolescent completed suicide. Arch Gen Psychiatry 1996;53:1155-1162.

8) Shaffer D, Gould MS, Fisher P, Trautman P, Moreau D, Kleinman M, et al. Psychiatric diagnosis in child and adolescent suicide. Arch Gen Psychiatry 1996;53:339-348.

9) Brent DA, Perper JA, Moritz G, Allman C, Friend A, Roth C, et al. Psychiatric risk factors for adolescent suicide: a case-control study. J Am Acad Child Adolesc Psychiatry 1993;32:521-529.

10) Pavot W, Diener E. Review of the satisfaction with life scale. Psychological Assesment 1993;5:164-172.

11) Flanagan JC. A research approach to improving our quality of life. American Psychologist 1978;33:138-147.

12) Rojas M. Life satisfaction and satisfaction in domains of life: is it a simple relationship? J Happiness Stud 2006;7:467-497.

13) Valois RF, Zullig KJ, Huebner ES, Drane JW. Life satisfaction and suicide among high school adolescents. Social Indicators Research 2004;66:81-105.

14) Fujino Y, Mizoue T, Tokui N, Yoshimura T. Prospective cohort study of stress, life satisfaction, self-rated health, insomnia, and suicide death in Japan. Suicide and Life-Threatening Behavior 2005;35:227-237.

15) Yao YS, Chang WW, Jin YL, Chen Y, He LP, Zhang L. Life satisfaction, coping, self-esteem and suicidal ideation in Chinese adolescents: a school-based study. Child Care Health Dev 2014;40: 747-752.

16) Kim H, Choi SH, Lee SE, Lee CW, Maeng S, Kim WH, et al. Variables affecting attitudes towards suicide among the adolescent population. J Nerv Ment Dis 2021;209:59-64.

17) Radloff LS. The CES-D scale: a self-report depression scale for research in the general population. Appl Psychol Meas 1977;1:385401.

18) Eaton WW, Smith C, Ybarra M, Muntaner C, Tien A. Center for Epidemiologic Studies Depression Scale: review and revision (CESD and CESD-R). In: Maruish ME, editor. The use of psychological testing for treatment planning and outcomes assessment: instruments for adults. 1st ed. Mahwah: Lawrence Erlbaum Associates Publishers;2004. p.363-377.

19) Lee S, Oh ST, Ryu SY, Jun JY, Lee K, Lee E, et al. Validation of the Korean version of Center for Epidemiologic Studies Depression Scale-Revised (K-CESD-R). Korean J Psychosom Med 2016;24: 83-93.

20) Cho MJ, Hahm BJ, Suh DW, Hong JP, Bae JN, Kin JK, et al. Development of a Korean version of the Composite International Diagnostic Interview (K-CIDI). J Korean Neuropsychiatr Assoc 2002; 41:123-137.

21) Belsley DA, Kuh E, Welsch RE. Regression diagnostics: identifying influential data and sources of collinearity. 2nd ed. New Jersey: John Willey \& Sons, Inc., Publication;2004. p.112-191.

22) Baron RM, Kenny DA. The moderator-mediator variable distinc- 
tion in social psychological research: conceptual, strategic, and statistical considerations. J Pers Soc Psychol 1986;51:1173-1182.

23) Kim MY, Kim JM. A study on the influencing mental health factors to suicidal ideation in adolescents. Korean J Youth Stud 2013; 20:267-293.

24) Sohn SY. Factors affecting suicidal ideation, suicidal plan and suicidal attempt in Korean adolescents. Journal of the Korea Academia-Industrial Cooperation Society 2014;15:1606-1614.

25) Huebner ES. Preliminary development and validation of a multidimensional life satisfaction scale for children. Psychol Assess 1994;6:149-158.

26) Diener E. Subjective well-being. Psychol Bull 1984;95:542-575.

27) Ohring R, Graber JA, Brooks-Gunn J. Girls' recurrent and con- current body dissatisfaction: correlates and consequences over 8 years. Int J Eat Disord 2002;31:404-415.

28) Kim JH, Kim KH. Analysis on influence of triggering variables related the suicidal ideation, suicidal plan, and suicidal attempt: focused on participants in 6th KoWePS. The Journal of the Korea Contents Association 2018;18:344-360.

29) Kim SY, Baek HJ. The construction of Korean youth happiness index. Korean Journal of Sociology 2008;42:140-173.

30) Organization for Economic Cooperation and Development (OECD). OECD guidelines on measuring subjective well-being. [cited 2021 Jan 5]. Available from URL: https://doi. org/10.1787/9789264191655-en. 


\begin{tabular}{|c|c|c|c|c|c|c|}
\hline \multirow{2}{*}{$X \rightarrow Y$} & \multicolumn{2}{|c|}{ Variable } & \multirow{2}{*}{ B } & \multirow{2}{*}{ SE } & \multirow{2}{*}{ OR (Exp B) } & \multirow{2}{*}{$p$} \\
\hline & Y & X & & & & \\
\hline \multirow[t]{10}{*}{ Step 1} & DEP & Sex & 0.721 & 0.185 & 2.06 & $<0.001$ \\
\hline & & FAM & -0.045 & 0.087 & 0.96 & 0.603 \\
\hline & & RELI & -0.293 & 0.178 & 0.75 & 0.100 \\
\hline & & EXE & -0.049 & 0.139 & 0.95 & 0.725 \\
\hline & & SES & 0.096 & 0.106 & 1.1 & 0.362 \\
\hline & & HAP & 0.817 & 0.164 & 2.26 & $<0.001$ \\
\hline & & AS & 0.168 & 0.136 & 1.18 & 0.218 \\
\hline & & LTS & 0.103 & 0.118 & 1.11 & 0.380 \\
\hline & & PHS & 0.191 & 0.116 & 1.21 & 0.098 \\
\hline & & MHS & 0.741 & 0.114 & 2.1 & $<0.001$ \\
\hline \multirow[t]{10}{*}{ Step 2sı } & SI & Sex & 0.427 & 0.168 & 1.53 & 0.011 \\
\hline & & FAM & -0.085 & 0.082 & 0.92 & 0.299 \\
\hline & & RELI & 0.055 & 0.164 & 1.06 & 0.737 \\
\hline & & EXE & -0.074 & 0.128 & 0.93 & 0.563 \\
\hline & & SES & 0.074 & 0.097 & 1.08 & 0.445 \\
\hline & & HAP & 0.286 & 0.146 & 1.33 & 0.050 \\
\hline & & AS & 0.437 & 0.126 & 1.55 & $<0.001$ \\
\hline & & LTS & 0.125 & 0.107 & 1.13 & 0.241 \\
\hline & & PHS & 0.026 & 0.107 & 1.03 & 0.804 \\
\hline & & MHS & 0.639 & 0.105 & 1.9 & $<0.001$ \\
\hline Step 2sp & SP & Sex & 0.371 & 0.252 & 1.45 & 0.142 \\
\hline & & FAM & 0.083 & 0.114 & 1.09 & 0.469 \\
\hline & & RELI & -0.332 & 0.239 & 0.72 & 0.167 \\
\hline & & EXE & -0.203 & 0.184 & 0.82 & 0.270 \\
\hline & & SES & 0.364 & 0.139 & 1.44 & 0.009 \\
\hline & & HAP & 0.273 & 0.205 & 1.31 & 0.183 \\
\hline & & AS & 0.141 & 0.178 & 1.15 & 0.428 \\
\hline & & LTS & -0.164 & 0.159 & 0.85 & 0.303 \\
\hline & & PHS & -0.119 & 0.153 & 0.89 & 0.436 \\
\hline & & MHS & 0.762 & 0.149 & 2.14 & $<0.001$ \\
\hline Step 2sa & SA & Sex & 0.577 & 0.277 & 1.78 & 0.037 \\
\hline & & FAM & 0.108 & 0.121 & 1.11 & 0.376 \\
\hline & & RELI & -0.200 & 0.259 & 0.82 & 0.440 \\
\hline & & EXE & -0.204 & 0.198 & 0.82 & 0.303 \\
\hline & & SES & 0.139 & 0.149 & 1.15 & 0.352 \\
\hline & & HAP & 0.286 & 0.223 & 1.33 & 0.200 \\
\hline & & AS & 0.399 & 0.192 & 1.49 & 0.037 \\
\hline & & LTS & -0.297 & 0.175 & 0.74 & 0.089 \\
\hline & & PHS & 0.078 & 0.160 & 1.08 & 0.626 \\
\hline & & MHS & 0.607 & 0.157 & 1.83 & $<0.001$ \\
\hline Step 3sı & $\mathrm{SI}$ & Sex & 0.319 & 0.173 & 1.38 & 0.065 \\
\hline & & FAM & -0.076 & 0.083 & 0.93 & 0.358 \\
\hline & & RELI & 0.109 & 0.168 & 1.12 & 0.518 \\
\hline & & EXE & -0.063 & 0.131 & 0.94 & 0.629 \\
\hline & & SES & 0.051 & 0.098 & 1.05 & 0.602 \\
\hline & & HAP & 0.142 & 0.151 & 1.15 & 0.347 \\
\hline & & AS & 0.429 & 0.128 & 1.54 & $<0.001$ \\
\hline & & LTS & 0.114 & 0.109 & 1.12 & 0.294 \\
\hline & & PHS & -0.016 & 0.109 & 0.98 & 0.886 \\
\hline & & MHS & 0.522 & 0.109 & 1.69 & $<0.001$ \\
\hline & & DEP & 1.025 & 0.194 & 2.79 & $<0.001$ \\
\hline Step 3sp & $S P$ & Sex & 0.231 & 0.259 & 1.26 & 0.372 \\
\hline & & FAM & 0.095 & 0.114 & 1.1 & 0.402 \\
\hline & & RELI & -0.299 & 0.242 & 0.74 & 0.217 \\
\hline & & EXE & -0.211 & 0.188 & 0.81 & 0.261 \\
\hline & & SES & 0.336 & 0.139 & 1.4 & 0.016 \\
\hline & & HAP & 0.102 & 0.21 & 1.11 & 0.628 \\
\hline & & AS & 0.137 & 0.176 & 1.15 & 0.434 \\
\hline & & LTS & -0.187 & 0.162 & 0.83 & 0.247 \\
\hline & & PHS & -0.168 & 0.155 & 0.85 & 0.278 \\
\hline & & MHS & 0.649 & 0.154 & 1.91 & $<0.001$ \\
\hline & & DEP & 1.031 & 0.287 & 2.8 & $<0.001$ \\
\hline Step 3 SA & SA & Sex & 0.398 & 0.286 & 1.49 & 0.163 \\
\hline & & FAM & 0.121 & 0.121 & 1.13 & 0.317 \\
\hline & & RELI & -0.138 & 0.264 & 0.87 & 0.601 \\
\hline & & EXE & -0.221 & 0.203 & 0.8 & 0.278 \\
\hline & & SES & 0.108 & 0.149 & 1.11 & 0.471 \\
\hline & & HAP & 0.075 & 0.228 & 1.08 & 0.743 \\
\hline & & AS & 0.377 & 0.189 & 1.46 & 0.047 \\
\hline & & LTS & -0.34 & 0.179 & 0.71 & 0.058 \\
\hline & & PHS & 0.008 & 0.164 & 1.01 & 0.960 \\
\hline & & MHS & 0.463 & 0.165 & 1.59 & 0.005 \\
\hline & & DEP & 1.386 & 0.315 & 4 & $<0.001$ \\
\hline
\end{tabular}

Step 1: logistic regression for the effect of independent variables on depression (mediator). Step 2: logistic regression for the effect of independent variables on suicidality. Step 3: logistic regression for the effect of independent variables and depression on suicidality. AS: appearance satisfaction, B. coefficient, DEP: depression, EXE. exercise, FAM: number of family numbers, HAP: religious affliation, SA: suicidal attempt, SE: standardized error, SES: perceived socioeconomic status, SI: suicidal ideation, SP: suireligious affiliation, SA: sUicidal attempt, SE: standardized error, SES: perceived socioeconomic status, SI: sUicidal ideation, SP: SUI- 
Supplementary Table 2. Significance test of the mediation effect

\begin{tabular}{lccccrr}
\hline Mediation effect & $\mathrm{A}$ & $\mathrm{B}$ & $\mathrm{SE}$ & $\mathrm{SE}$ & \multicolumn{1}{c}{$\mathrm{Z}$} & $\mathrm{P}$ \\
\hline $\mathrm{Sex} \rightarrow \mathrm{DEP} \rightarrow \mathrm{SI}$ & 0.721 & 1.025 & 0.185 & 0.194 & 3.136 & 0.002 \\
$\mathrm{MHS} \rightarrow \mathrm{DEP} \rightarrow \mathrm{SI}$ & 0.741 & 1.025 & 0.114 & 0.194 & 4.099 & $<0.001$ \\
$\mathrm{MHS} \rightarrow \mathrm{DEP} \rightarrow \mathrm{SP}$ & 0.741 & 1.031 & 0.114 & 0.287 & 3.144 & 0.002 \\
$\mathrm{Sex} \rightarrow \mathrm{DEP} \rightarrow \mathrm{SA}$ & 0.721 & 1.386 & 0.185 & 0.315 & 2.917 & 0.004 \\
$\mathrm{MHS} \rightarrow \mathrm{DEP} \rightarrow \mathrm{SA}$ & 0.741 & 1.386 & 0.114 & 0.315 & 3.644 & $<0.001$ \\
\hline
\end{tabular}

The Sobel test was performed on the dataset shown in Supplementary Table 1. A=coefficient for the relationship between the independent variable and the mediator; $B=$ coefficient for the relationship between the mediator and the dependent variable; $\mathrm{SE}_{\mathrm{A}}=$ standard error of the relationship between the independent variable and the mediator; $\mathrm{SE}_{\mathrm{B}}=$ standard error of the relationship between the mediator and the dependent variable. DEP: depression, MHS: mental health satisfaction, SA: suicidal attempt, SI: suicidal ideation, SP: suicidal plan 